\title{
A inquietude da mata atlântica: reflexões sobre a política do abandono em uma terra cobiçada
}

\author{
The restlessness of the atlantic rainforest: \\ reflections on the abandonment policy in a coveted land
}

Liliani Marilia Tiepolo ${ }^{1}$

\begin{abstract}
Resumo
Apresenta-se uma base para reflexões e diálogos em torno da Mata Atlântica, aqui inquieta, não somente pelo seu atual estado de perturbação ecológica, mas também pela inquietude de seus integrantes, sua biodiversidade e sua população local nativa. Devido ao grande valor ecossistêmico da região, muitas alternativas de conservação da natureza têm sido implementadas desde a década de 1980, porém pouca efetividade tem sido observada na prática, o que gera inúmeros conflitos ambientais, deixando de promover formas de desenvolvimento alternativo, por um lado, e fortalecendo os modelos desenvolvimentistas dos setores produtivos público-privados. Conclui-se que a vocação da região para empreender modelos de desenvolvimento diferenciados, práticas inovadoras, experiências alternativas com respeito às singularidades ecológicas e culturais é drasticamente afetada e obstruída por uma orquestrada política intencional de abandono, com fins a transformar toda a região em polo industrial de empreendimentos de grande impacto ambiental.
\end{abstract}

Palavras-chave: Mata Atlântica; Litoral do Paraná; Política do abandono; Desenvolvimento.

\begin{abstract}
Presents a basis for reflections and dialogues around the forest, here restless, not only by its current state of ecological disturbance but also by the concern of its members, its biodiversity and its local people. Due to the large ecosystem value of the region, many nature conservation alternatives have been implemented since the 1980s, but little effect has been observed in practice, which creates numerous environmental conflicts failing to promote forms of alternative development on the one hand and strengthening the developmental models of public-private sectors. We conclude that the vocation of the region to undertake different development models, innovative practices, alternative experiences with respect to ecological and cultural singularities is drastically affected and obstructed by a deliberate orchestrated abandonment policy, with purpose to transform the entire region into industrial center of major environmental impact projects.
\end{abstract}

Keywords: Atlantic Rain Forest; Coast of Paraná; Abandonment policy; Development.

\footnotetext{
1 Doutora em Zoologia (Museu Nacional/UFRJ). Professora do Programa de Pós-Graduação em Desenvolvimento Territorial Sustentável, da Universidade Federal do Paraná. E-mail: liliani@ufpr.br.
} 
Por todos os meios possíveis, trata-se de conjurar o crescimento entrópico da subjetividade dominante. Em vez de ficar perpetuamente ao sabor da eficácia falaciosa de "challenges" econômicos, trata-se de se reapropriar de Universos de valor no seio dos quais processos de singularização poderão reencontrar consistência. Novas práticas sociais, novas práticas estéticas, novas práticas de si na relação com o outro, com o estrangeiro, com o estranho: todo um programa que parecerá bem distante das urgências do momento! E, no entanto, é exatamente na articulação: da subjetividade em estado nascente, do socius em estado mutante, do meio ambiente no ponto em que pode ser reinventado, que estará em jogo a saída das crises maiores de nossa época.

Félix Guattari, As três ecologias, p. 55, 1989.

\section{A terra cobiçada e sua gente}

A região costeira do Paraná ocupa uma área de $6.058 \mathrm{~km}^{2}$ do bioma Mata Atlântica. Localmente é representada por diversas fisionomias vegetais em grande parte florestais e caracterizada pelas formas de relevo da Serra do Mar e da Planície Litorânea. Entre ambientes naturais biodiversos de extremo valor ecológico e as paisagens modificadas historicamente, vivem cerca de 265.362 habitantes em sete municípios com populações entre 7.000 habitantes, em Guaraqueçaba, até 140.450, em Paranaguá (IBGE, 2012). A economia regional é diferenciada em cada município, mas pode ser simplificada pelas principais formas atuais do uso do solo costeiro: portuário, agrícola, pesqueiro, turístico e destinado à conservação dos ecossistemas e sua biodiversidade (PIERRI et al., 2006).

Estas paisagens representam os últimos remanescentes contínuos de floresta atlântica costeira do Brasil e ainda encontram-se relativamente bem conservados graças às características geomorfológicas regionais, aos processos históricos de ocupação do litoral e à presença de Unidades de Conservação. Figuram também entre os principais hotspots de biodiversidade do planeta e abrangem o Mosaico de Áreas Protegidas do Lagamar. Devido a essas particularidades, diversas iniciativas de conservação começaram a ter efeito a partir da década de 1980, quando iniciou-se o processo de criação de Unidades de Conservação no litoral, embora com baixo nível de consolidação devido a equívocos conceituais, problemas fundiários, erros na demarcação dos limites e ausência de políticas públicas voltadas à conservação da natureza e participação social. O não reconhecimento dos territórios de povos tradicionais amplifica a imbricada rede de conflitos ambientais que permeiam todo o litoral do 
Paraná, trazendo à tona elementos de uma política do abandono propositalmente instalada nestes confins.

O litoral do Paraná tem sua história marcada pelas sucessivas investidas dos invasores portugueses contra territórios indígenas a partir de $1585 \mathrm{com}$ a finalidade de escravizar os índios. As chamadas "bandeiras" resultaram em grande extermínio e massacre dos Guaranis em toda sua ampla área de distribuição. Em História Geral das Bandeiras Paulistas, Afonso D'Escragnolle Taunay nos oferece uma rica historiografia da passagem dos bandeirantes pela história do Brasil. Em Paranaguá, conforme se percebe nos relatos da História do Paraná, a partir da obra de Romário Martins, de 1937 (p. 31):

Carijós [Guaranis]. Dominadores de toda a costa marítima, de Cananéia a Lagoa dos Patos. Atacados e preados em grandes levas na região de Paranaguá pela "bandeira" de Jerônimo Leitão, em 1585. Pouco antes de 1640, Gabriel de Lara ${ }^{2}$, ao procurar estabelecer-se em Paranaguá, receou a hostilidade do gentio Carijó possivelmente ainda ressentido do assalto bandeirante de 1585 , e prudentemente se localizou com sua expedição na Ilha da Cotinga ${ }^{3}$, fronteira ao continente, para onde se transferiu depois, fundando a vila de Nossa Senhora do Rosário de Paranaguá. Tendo captado a confiança dos índios, deles se serviu para a descoberta e a exploração de ouro. Assim foi que os carijós da costa paranaguense que não foram escravizados pela "bandeira" preadora ou que não se internaram no sertão fugindo a outras agressões dos brancos, passaram a constituir o lastro da nossa população litorânea. Ainda hoje a nossa gente praieira conserva o tipo do seu ascendente indígena.

Destes povos autóctones intensamente perseguidos, muitos sobreviventes acabaram por se miscigenar com portugueses estabelecidos aqui desde as épocas das grandes navegações ${ }^{4}$ e das bandeiras e ao longo do tempo com outros grupos étnicos que por aqui chegaram. Nos vastos meandros das baías circundadas por ricos manguezais e florestas úmidas estabeleceram um modo de vida próprio baseado em cultivos de subsistência, pesca, caça e com muitas particularidades culturais. No entanto, entre capitanias hereditárias, ataques de bandeirantes, mineração do ouro, extração de madeira e a consolidação do Paraná, isolados pela geografia, sua gente continuou esquecida, ou segundo Ferreira et al. (2011), ao tratar comunidades rurais nos fundos da Baía de Guaratuba, invisíveis.

Foram sucessivos governos que mantiveram grande parte do litoral em abandono. Até que houve algumas intenções de desenvolvimento que propiciaram muitas das mudanças

\footnotetext{
2 Capitão-povoador, fundador da Vila de Paranaguá em 1648 (MARTINS, 1937, p. 202).

${ }^{3}$ Reserva Indígena Ilha da Cotinga desde 1993 (FUNAI, 2015).

${ }^{4}$ Hans Staden em 1556 em seu "A verdadeira história e descrição de uma paisagem dos selvagens, nus e ferozes devoradores de homens encontrados no Novo Mundo (...)” relata em 1549 a presença de portugueses convivendo com índios "carijós" em Superagüi.
} 
vindouras. Foi assim que ainda em tempos imperiais foi construída a Estrada de Ferro que liga Curitiba a Paranaguá ${ }^{5}$. Também a construção da Rodovia, conhecida como Estrada da Graciosa, transformou-se em importante via comercial entre o litoral e o planalto. Mas nenhuma delas seria tão importante quanto aquela proporcionada por uma das características naturais da região e que sempre despertou o interesse político e econômico desde os tempos mais longínquos: a baía de Paranaguá possuía características para ser um imponente porto, o que de fato se deu em 1872. Mas somente no século XX tornou-se um estratégico porto, devido ao crescimento da indústria agrícola no sul do Brasil, impulsionada pelo agronegócio.

Hoje mais do que nunca, a cidade de Paranaguá carrega as marcas de um modelo de desenvolvimento desordenado, resultado da negligência, apatia e avidez política associada a apadrinhamentos empresariais. Incalculáveis riquezas geradas pouco deixaram para sua população, que continuou pelas décadas seguintes assistindo às levas de gentes "desenvolvidas" usurparem suas terras e aqui estabelecerem suas indústrias poluentes, seus altos edifícios, suas chácaras, seus comércios, suas estradas e seus modos de vida urbano. E parece nunca ter fim esse processo, agora tão acelerado que as culturas locais outrora esquecidas encontram-se ameaçadas de extinção tanto quanto as espécies endêmicas da Mata Atlântica em seus fragmentados habitat.

Os invisíveis vivem em grande parte em comunidades remotas de lavradores e pescadores artesanais espalhados pelo litoral em condições precárias de vida, sem acessos a serviços públicos básicos, com baixa ou nenhuma escolaridade, à mercê das especulações do Estado que não hesita em proporcionar condições legais para que seus encurralados territórios continuem sendo usurpados e seus direitos fundamentais tolhidos. Mas também vivem ao lado de grandes centros urbanos, na beira da praia, em recantos próximos a locais de interesse privado. Mas não são reconhecidos pelo Estado. Raramente são lembrados. Não possuem o papel, o título da terra, estão à margem do sistema capitalista industrial urbano e suas normativas. Sofrem em cada puxada de rede os efeitos deletérios dos impactos ambientais de inúmeros empreendimentos industriais que não cessam de se instalar na frágil e cobiçada região. Estão indo embora, obrigados a deixar seu lugar e modo de vida para se juntar às multidões que chegam no litoral todos os dias para ocupar as periferias ainda florestadas em busca dos sonhados empregos tão divulgados pelos grandes empreendimentos. Sofrem de

\footnotetext{
${ }^{5}$ A primeira "Maria-Fumaça" percorreu a ferrovia Curitiba-Paranaguá em fevereiro de 1880, "transportando passageiros e cargas, produto do trabalho do povo paranaense para os nossos portos marítimos, exportando o que nos sobrava e, na volta, trazendo aquilo que nos faltava". 1885-1985 - Ferrovia Paranaguá-Curitiba: uma viagem de 100 anos (RFFSA, 1985).
} 
invisibilidade, em ações coordenadas entre um Estado incapaz de cumprir seus objetivos básicos aliado às "pessoas jurídicas", que juntos propulsionam as molas do grande capital.

Tendo essa paisagem em foco, apresenta-se aqui uma base para reflexões e diálogos em torno da Mata Atlântica, aqui inquieta, não somente pelo seu atual estado de perturbação ecológica, mas também pela inquietude de seus integrantes, sua biodiversidade e sua população local autóctone. Baseou-se o ensaio nas andanças, pesquisas, conversas, experiências e observações realizadas na Mata Atlântica do Paraná, mas também na participação da autora em diversos fóruns locais ao longo dos últimos 20 anos. Contextualizase o litoral do Paraná tendo como base as riquezas socionaturais, sua biodiversidade e cultura para em seguida destacar de que forma opera a política do abandono propositalmente e historicamente instalada sobre a gestão dos espaços que deveriam ser especialmente protegidos, cujas consequências recaem não apenas sobre a população litorânea, mas sobre sua base ecossistêmica. Por fim, chama para o diálogo a necessidade de uma agenda socioambiental reconhecendo as características locais e os modos de vida conjugados com a vocação socionatural do lugar.

\section{A política do abandono na conservação da natureza}

No litoral do Paraná, 947.664,82 hectares do território são protegidos pelo Sistema Nacional de Unidades de Conservação, composto por 14 unidades estaduais, 8 federais e 11 privadas, totalizando 33 áreas naturais protegidas (Tabela 1). Uma análise menos atenta tende a considerar que todo o litoral é protegido, mas à luz das diferentes categorias de unidades de conservação observa-se que apenas 24,48\% (185.010,32 hectares) de área é destinada à proteção integral, ao passo que 75,52\% (571.059 hectares) são destinadas ao uso sustentável dos recursos, especialmente as Áreas de Proteção Ambiental, muito questionadas quanto à sua capacidade de conservação, como bem observa Firkowski (2007). Em seu crítico olhar sobre essa categoria de manejo, esse autor indaga se essas não seriam uma estratégia para enganar a sociedade. Uma maneira dissimulada de fazer a opinião pública se tornar distorcida em relação à conservação da natureza. E por quê? O autor se vale da afirmação de Maria Tereza Jorge Pádua (2006) sobre o assunto: 
Talvez não exageraríamos se disséssemos que é inútil em nosso país. Isso porque é a declaração de proteção de uma área que fica, em quase sua totalidade, nas mãos de particulares, onde as restrições de uso, portanto, são aquelas da legislação orgânica válida para qualquer propriedade do país. Em outras palavras, só se pode restringir em uma APA o mesmo que se pode restringir em qualquer outro lugar, APA ou não.

No entanto, essa categoria de unidade de conservação apresenta-se em extensão de forma bastante expressiva no sistema de áreas protegidas no Litoral do Paraná (e em todo o Brasil) e podemos considerar que é uma forma de conservação controvertida. E de fato, nos confins de Guaratuba se pulverizam venenos há anos, com avião, os monocultivos de banana que sobem e descem as áreas que outrora foram florestas ombrófilas submontanas e que deveriam ser protegidas pelo Código Florestal, aquele de 1965. Ou melhor: se pulveriza veneno no solo, nos rios, nas florestas, nos moradores, nos trabalhadores rurais, nas crianças, nos animais domésticos e nas bananas. Isso tudo em plena Área de Proteção Ambiental de Guaratuba. E não longe dali muito veneno é aplicado nas planícies brejosas onde se cultiva o arroz, e todos esses resíduos de agrotóxicos seguem rio abaixo para contaminar os estuários dessa baía.

Além das APAs, soma-se ainda 12.701,5 hectares de Reservas Particulares do Patrimônio Natural, manejadas na forma de proteção integral embora dentro da categoria de uso sustentável.

Envolto por uma aparente proteção ambiental, o litoral do estado do Paraná revela-se como área de elevada tensão ecossistêmica e social, percebida sobretudo pelas suas características naturais, mas especialmente pelo seu crescimento populacional, desigualdades sociais e pelas rápidas transformações nas dinâmicas de uso e ocupação do solo, o que configura uma região de grande vulnerabilidade socioambiental, especialmente no que diz respeito às consequências severas de eventos climáticos, como tempestades, vendavais, inundações e alagamentos sobre as populações humanas e seus meios de produção nas zonas urbanas e rurais. 
TABELA 1: ÁREA DE PROTEÇÃO (EM HECTARES) REPRESENTADA PELAS UNIDADES DE CONSERVAÇÃO DE PROTEÇÃO INTEGRAL E USO SUSTENTÁVEL.

\begin{tabular}{|c|c|c|c|c|c|}
\hline $\begin{array}{c}\text { Proteção Integral } \\
\text { Federal }\end{array}$ & $\begin{array}{c}\text { Proteção Integral } \\
\text { Estadual }\end{array}$ & $\begin{array}{c}\text { Uso Sustentável } \\
\text { Federal }\end{array}$ & $\begin{array}{c}\text { Uso Sustentável } \\
\text { Estadual }^{6}\end{array}$ & RPPN & $\begin{array}{c}\text { Área total em } \\
\text { hectares }\end{array}$ \\
\hline $156.629,51$ & $28.380,81$ & $291.498,00$ & $266.859,5$ & $12.701,5$ & $756.069,32$ \\
\hline \multicolumn{2}{|c|}{$\begin{array}{c}185.010,32 \\
24,48 \%\end{array}$} & & 571.059 & & \\
\hline
\end{tabular}

FONTE: IAP, ICMBio e MMA (Cadastro Nacional de UC) obtidos em 2015 nos sítios oficiais da internet.

É notável que a maior parte das unidades de conservação estaduais do litoral do Paraná encontra-se abandonada pelo poder público. As sucessivas mudanças de governo nas últimas três décadas pouco contribuíram para que as áreas naturais protegidas da região fossem consolidadas e implementadas. Desde o estabelecimento da primeira unidade de conservação, o Parque Florestal Rio da Onça em 1981, foram criadas outras 13. Destas, as únicas que contam com planos de manejo são a Área de Proteção Ambiental de Guaratuba, Área de Proteção Ambiental de Guaraqueçaba, Área de Especial Interesse Turístico do Marumbi, Estação Ecológica da Ilha do Mel, Estação Ecológica de Guaraguaçu e Parque Estadual do Pico Marumbi. No entanto, a maior parte está desatualizado e necessita de novas revisões conforme determina a legislação ${ }^{7}$. As unidades de conservação federais, embora possuam um número mínimo de analistas ambientais, enfrentam os mesmos problemas em relação à consolidação e o plano de manejo não faz parte do dia a dia da gestão das UCs. A única UC federal que possui o documento técnico de gestão é a APA de Guaraqueçaba, também desatualizado, e o Parque Nacional de Superagui está finalizando seu plano, após 26 anos de sua criação em 1989.

Outro essencial instrumento de gestão das UCs é o conselho gestor, seja ele deliberativo ou consultivo. Nesse caso, entre as UCs estaduais do litoral apenas a APA de Guaratuba possui um conselho deliberativo em funcionamento. As UCs da região não observam as condicionantes da legislação em vigor que dispõe sobre seu funcionamento e gestão, especialmente no que diz respeito ao cumprimento dos objetivos de conservação, elaboração do plano de manejo, consolidação dos conselhos consultivos e deliberativos,

\footnotetext{
${ }^{6}$ Há possíveis sobreposições de áreas de uso sustentável uma vez que coexistem duas APAs de Guaraqueçaba, uma federal com 291.498 hectares, criada em 1985; e outra estadual, com 191.595,50 hectares, criada em 1992. Para efeito desta contabilidade, considerou-se apenas a APA federal de Guaraqueçaba por possuir maior tamanho.

${ }^{7}$ Artigo 27, $3^{\circ}$ do Sistema Nacional de Unidades de Conservação (Lei $n^{\circ}$ 9.985, de 18 de julho de 2000)."O Plano de Manejo de uma unidade de conservação deve ser elaborado no prazo de cinco anos a partir da data de sua criação".
} 
estruturação do mosaico de unidades de conservação, desenvolvimento local, uso público, pesquisas científicas e educação ambiental. Já entre as unidades federais, o Parque Nacional Saint Hilaire Lange possui em funcionamento um conselho consultivo bastante atuante; também a Área de Proteção Ambiental de Guaraqueçaba o possui, o que evidencia que não é necessário possuir plano de manejo para se utilizar desse mecanismo de gestão tão importante, mas sim um quadro mínimo de analistas ambientais.

Com 33 Unidades de Conservação na região, se esperaria que estas promovessem a vocação intrínseca do litoral do Paraná, dado suas belezas cênicas, a cultura diferenciada de sua gente nativa com seu modo de vida peculiar, suas florestas biodiversas com inúmeras espécies endêmicas e ameaçadas - até porque é objetivo comum dessas áreas que, para além de conservarem a biodiversidade, recursos hídricos, paisagens cênicas, recursos genéticos etc., que também promovam o desenvolvimento local, conforme enuncia o SNUC (2001) em seus objetivos. Porém, não é o que se dá porque não existe uma política socioambiental no estado do Paraná para cumprir as determinações legais e executar suas políticas derivadas. Soma-se ainda que no âmbito federal coexistem sérios problemas que vão desde as influências políticas permeando o campo da gestão pública até o reduzido número de analistas presentes nas UCs. No litoral do Paraná poucas são as UCs que contemplam um quadro mínimo de pessoas com competências para o gerenciamento ambiental. Nas UCs estaduais, por exemplo, um único gestor chega a ser responsável por até três unidades. Não obstante, a forma de gestão de algumas UCs ainda se mantém autoritária e repressora, centrada na fiscalização e na força policial, gerando quadros que agravam os já existentes conflitos ambientais, no lugar de promoção dos processos participativos e do desenvolvimento voltados para a vocação da região.

Muitos autores se referem a conflitos com populações locais residentes no interior de UC ou no seu entorno, entre os quais Diegues \& Nogara (1999), Arruda (2000), Diegues (2000), Gomes et al. (2004), Soares \& Irving (2006), Camargo (2011), Pérez \& Gómez (2014) e Giraldi-Costa \& Murata (2015). Em comum, esses autores se referem à falta de reconhecimento dos territórios tradicionais pelo Estado, o que de fato está no cerne dos conflitos ambientais envolvendo Unidades de Conservação no Brasil. Por outro lado, a Estratégia Global da Biodiversidade (WRI, 1992) salienta que o melhor modo de fortalecer as áreas protegidas consiste em conjugá-las com as necessidades econômicas e sociais locais. Nesse sentido, os processos participativos têm trazido contribuições valiosas à gestão das UCs, que vão desde as possibilidades de trabalho e os benefícios dos serviços ecossistêmicos por elas prestados até a participação direta no processo de gestão. Irving et al. (2008) ao focar 
criticamente os processos de gestão dos Parques Estaduais do Rio de Janeiro, vão nos apresentar possíveis novos caminhos e maneiras de pensar e agir sobre a gestão de áreas protegidas no país, em contextos ampliados a partir das interfaces com a dinâmica social, mas também observando um país em processo de transformação.

Por outro lado, um documento interessante foi recentemente elaborado por Medeiros (2011) para o Ministério do Meio Ambiente, que apresenta a contribuição das UC para a economia nacional, embora neste documento as UC sejam tratadas no contexto da macroeconomia, o que temos assistido são ameaças cada vez maiores aos seus processos de criação e aos seus limites, especialmente advindas dos setores produtivos ligados à agricultura, pecuária, mineração e dos projetos de desenvolvimento do Governo Federal, notavelmente no Cerrado e na Amazônia (KLINK \& MACHADO, 2005; FEARNSIDE, 2005; ARAÚJO et al. 2013). No entanto, a Mata Atlântica não ficou de fora dos grandes projetos de infraestrutura; o Pré-Sal é um dos exemplos do quanto ainda está por vir em termos de desmatamento, realocação de pessoas, populações tradicionais e impactos ambientais sobre ecossistemas especialmente protegidos ou não.

Ao mesmo tempo, uma breve análise do SNUC (2001) revela uma série de inovações sobre a forma de gestão que era conduzida anteriormente à promulgação dessa lei, entre as quais destacam-se o Artigo $5^{\circ}$ (III, V, IX), que assegura e incentiva a participação efetiva das populações locais na criação, implantação e gestão das UCs. Aponta diretrizes que considerem as condições e necessidades das populações locais no desenvolvimento e adaptação de métodos e técnicas de uso sustentável dos recursos naturais. O Artigo 27 garante que o Plano de Manejo deve incluir medidas para a promoção da integração à vida econômica e social das comunidades vizinhas. O Artigo 29 garante participação de populações tradicionais residentes no Conselho Consultivo da UC. O Artigo 30 incentiva a gestão da UC por organizações da sociedade civil de interesse público.

Mesmo a legislação apontando significativa abertura à participação da sociedade, se as áreas não possuem quadro efetivo de profissionais para exercer cargos de alta complexidade, de nada adianta as inovações da lei. Também vale a ressalva de que ainda estamos nos primórdios da gestão pública com participação social no Brasil. Nesse cenário, não somente a Unidade de Conservação fica à mercê dos processos destrutivos que operam por força dos mercados industriais, como a população sofre diretamente os danos advindos das externalidades quando esses processos se instalam no lugar. Este é o caso em evidência no litoral do Paraná, onde 18 projetos desenvolvimentistas de infraestrutura já estão licenciados e outros tantos em vias de licenciamento ambiental, conforme nos aponta os resultados dos 
estudos de Goes (2014). Tratam-se de novas estruturas portuárias e novas rodovias sobrepujando territórios tradicionais, até complexos industriais poluidores sendo instalados no entorno imediato de unidades de conservação, promovendo grandes transformações nas dinâmicas sociais nas cidades. Os estudos de Sezerino \& Tiepolo (2015) analisam o processo de criação de um bairro novo no município de Paranaguá, instalado em um loteamento consolidado para esse fim, do Programa do Governo Federal Minha Casa Minha Vida, no entorno da Floresta Estadual do Palmito, para realocar a população de uma área considerada de risco, mas destinada à expansão do Porto de Paranaguá.

Aqui cabe a consideração de que todo o arcabouço jurídico ambiental consolidado com suas inovações que vêm abrindo espaço para o fortalecimento das organizações sociais, não somente na gestão das áreas naturais protegidas, está sendo propositalmente negligenciado, flexibilizado e prevaricado no litoral do Paraná. Aqui percebe-se claramente a inquietude da Mata Atlântica mais bem conservada do Brasil: nas últimas três décadas, conduziu-se um grande esforço para criar 33 Unidades de Conservação, mas a gestão desse complexo sistema de proteção é em grande medida baseada em uma orquestrada política do abandono, da exclusão e da invisibilidade social. Nem estamos tratando aqui de outras tipologias de áreas protegidas, como territórios quilombolas e terras indígenas, onde a situação chega a ser pior e de grandes incertezas.

\section{Uma agenda socioambiental para o litoral do Paraná}

As reflexões aqui expostas levam para o entendimento de que o litoral do Paraná abrange um frágil ecossistema de uma das mais ameaçadas tipologias florestais do planeta, a Mata Atlântica, e que nesse ecossistema biodiverso coexistem populações e comunidades autóctones indígenas e comunidades com características tradicionais, reconhecidas como caiçaras $^{8}$. Que a região possui vocação para outros modelos alternativos de desenvolvimento baseado em sua natureza e cultura. Que é cobiçada pelo seu elevado valor para determinados setores da economia, como aqueles relacionados à exportação de commodities, importação de agrotóxicos, turismo de praia e sol e pelo setor imobiliário orientado para a construção de imóveis verticalizados para veraneio. Que para salvaguardar esses ecossistemas litorâneos e suas gentes não é mais possível utilizar-se de dicotomias históricas baseadas nos embates

\footnotetext{
${ }^{8}$ As populações litorâneas que apresentam ligações com a terra por meio da lavoura de subsistência, pesca e extrativismo, através da relação de parentesco e ajuda mútua (DIEGUES, 1983).
} 
entre ciências naturais e sociais. A arena de embates não pode estar pautada na opressão, na fragilização, na vulnerabilização nem na negação de direitos fundamentais de pessoas, grupos familiares e comunidades que utilizam e ocupam o solo e a natureza para sua subsistência. Pelo contrário: enquanto famílias são hostilizadas pelo poder público porque estão caçando e extraindo palmito, samambaias, madeira, cipós, entre outros produtos florestais não madeiráveis da floresta, o mesmo poder público está licenciando várias obras que irão derrubar dezenas de hectares de florestas nativas e protegidas por lei para a instalação de indústrias poluidoras, em grande parte de capital estrangeiro, que pouco ou nenhum compromisso social possuem com a região e com frequência praticam um modus operandi organizado para expulsar grupos sociais fragilizados de seus territórios, como por exemplo os pescadores artesanais.

São notáveis os casos de perseguição contra grupos sociais no litoral do Paraná para atender a interesses de grupos econômicos hegemônicos e do poder público, que não raras vezes é aliado desses segmentos contra a manutenção das territorialidades existentes, promovendo pressão para o desaparecimento desses modos de vida. Aqui cabe destaque os estudos empenhados por Ferreira et al. (2011) sobre a comunidade de lavradores de São Joãozinho, nos confins da Área de Proteção Ambiental de Guaratuba; os de Camargo (2011)e os de Pérez \& Gómez (2014), ambos realizados na Vila de Superagui, em Guaraqueçaba; os estudos de Harder (2014) na comunidade de pescadores da Ponta Oeste, na Ilha do Mel; e os de Giraldi-Costa \& Murata (2015) com a comunidade de pescadores artesanais de Matinhos. Mas também tantos outros não menos relevantes, como as tensões e conflitos a que estão submetidos os agricultores familiares na Área de Proteção Ambiental de Guaraqueçaba, as pressões e agressões que os pescadores artesanais da Vila do Maciel vêm sofrendo há anos para ceder seu lugar em Pontal do Paraná e a completa retirada dos pescadores da localidade conhecida como Ponta do Poço, lugar historicamente ocupado por eles e que hoje é o mais cobiçado ponto para a implantação de mais um porto privado de grandes dimensões, cujo licenciamento é no mínimo polêmico. Ou seja, no litoral do Paraná está em franca operação um poderoso e despótico processo de desterritorialização, o lugar daquelas formas concretas e simbólicas de apropriação e uso do espaço pelas comunidades locais, sejam elas empreendidas por caiçaras, agricultores familiares ou por pescadores artesanais. Essas disputas, nem sempre evidentes, trazem mostras das relações assimétricas de poder e dominação e repercutem diretamente nas significações de identidade e lugar dos grupos alvos, geralmente sujeitados, marginalizados e vulnerabilizados. Estamos no campo dos conflitos ambientais, sejam eles de ordem distributiva, espacial ou territorial, todos coexistindo para dar 
lugar aos novos territórios de expansão da sociedade urbana, industrial, capitalista e global, que não abre mão da chantagem da localização ${ }^{9}$ sobre os entes públicos e sociedade civil para conquistar seu novo espaço de produção e apropriação.

Tendo como referência as experiências acumuladas ao longo dos últimos 20 anos com participação social e percepções a partir do litoral do Paraná e muito longe de pretender esgotar o assunto, pelo contrário, a partir de olhares transversais, parece óbvio que é necessário somar esforços no sentido da construção de uma agenda socioambiental para a região, com vistas a abrir e ou ampliar os caminhos que precisam ser trilhados rumo a um modelo contracorrente de desenvolvimento que tenha como referência pragmática a justiça ambiental. Tem-se em vista que é responsabilidade pública resguardar a sociobiodiversidade da Mata Atlântica em sua região mais bem conservada, com o cuidado de entender que o Estado é um ente de relações dúbias: ora age como intermediário facilitador de processos geradores de impacto para benefício de grandes corporações; cria mecanismos para alterar marcos regulatórios, como por exemplo as intenções de alteração do Decreto Estadual $n^{\circ}$ 2722/1984 e as recentes e polêmicas mudanças no Código Florestal; ora cria instrumentos para assegurar o modo de vida dos povos tradicionais, como por exemplo a criação da Política Nacional de Desenvolvimento Sustentável dos Povos e Comunidades Tradicionais (Decreto $\left.n^{0} 6040 / 2007\right)$.

\section{Referências}

ACSELRAD, H. Justiça ambiental: ação coletiva e estratégias argumentativas. In: ACSELRAD, H.; HERCULANO, S.; PÁDUA, J. A. (Orgs.). Justiça ambiental e cidadania. Rio de Janeiro: Relume Drumará, 2004.

ARAÚJO, E.; MARTINS, H.; BARRETO, P.; LIMA, A. C. Áreas protegidas da Amazônia Legal com mais alertas em 2012 - 2013. Belém: Instituto do Homem e Meio Ambiente da Amazônia (Imazon), 2013.

ARRUDA, R. S. V. Populações tradicionais e a proteção dos recursos naturais em Unidades de Conservação. In: DIEGUES, A. C. (Org.). Etnoconservação: novos rumos para a proteção da natureza nos trópicos. São Paulo: Nupaub - USP, 2000.

\footnotetext{
${ }^{9}$ Segundo Acselrad (2004), no contexto da globalização econômica, o capital retira sua força da capacidade de se deslocalizar, enfraquecendo os atores sociais atuais menos móveis - governos locais e sindicatos, por exemplo e desfazendo pela chantagem da localização, normas governamentais urbanas ou ambientais, bem como conquistas sociais.
} 
CAMARGO, L. Conflitos socioambientais: desafios e oportunidades para o desenvolvimento local da Barra do Superagui. Dissertação (Mestrado em Politiche Ambientali e Territoriali)- Università Degli Studi Di Ferrara, Itália, 2011.

DIEGUES, A. C. Pescadores, camponeses e trabalhadores do mar. São Paulo: Ática, 1983.

DIEGUES, A. C. Etnoconservação da natureza: enfoques alternativos. In: DIEGUES, A. C. (Org.). Etnoconservação: novos rumos para a proteção da natureza nos trópicos. São Paulo: Nupaub - USP, 2000.

DIEGUES, A. C.; NOGARA, P. J. Nosso lugar virou parque: estudo socioambiental do Saco do Mamanguá, Parati, Rio de Janeiro. São Paulo: Nupaub - USP, 1999.

FEARNSIDE, P. M. Desmatamento na Amazônia brasileira: história, índices e consequências. Megadiversidade, v. 1, n. 1, p. 113-123, 2005.

FERREIRA, M. R.; NEGRELLE, R. R. B.; ZANATTA, R. A. F. Terra inválida, gente invisível: o caso das comunidades rurais extrativistas do litoral paranaense. In: DENARDIN, V. F.; ABRAHÃO, C. M. de S.; QUADROS, D. A. (Orgs.). Litoral do Paraná: reflexões e interações. Matinhos: Editora UFPR Litoral, 2011.

FIRKOWSKI, C. APA: fatos, desejos sonhados e propagandice. Natureza \& Conservação, v. 5 , n. 1, p. $8-14,2007$.

GIRALDI-COSTA, A. C.; MURATA, A. T. Conflitos socioambientais na criação de Unidades de Conservação: o caso do Parque Nacional Marinho das Ilhas dos Currais. Revista Hipótese, v. 1, n. 3, p. 48-63, 2015.

GOES, L. M. Conservação e grandes empreendimentos de infraestrutura no litoral do Paraná: a ferrovia Lapa-Paranaguá. 2014, 108 f. Dissertação (Mestrado em Meio Ambiente e Desenvolvimento)- Universidade Federal do Paraná, Curitiba, 2014.

GOMES, L. J; CARMO, M. S.; SANTOS, R. F. Conflitos de interesses em Unidades de Conservação do Município de Parati, estado do Rio de Janeiro. Informações Econômicas, v. 34, n. 6, p. 17-27, 2004.

GUATTARI, F. As três ecologias. Campinas: Papirus, 1993.

HARDER, E. A constitucionalização dos direitos culturais no Brasil e os sentidos de uma perspectiva patrimonial. Tese (Doutorado em Direito das Relações Sociais)- Setor de Ciências Jurídicas, Universidade Federal do Paraná, Curitiba, 2014.

IBGE. Censo da população brasileira. Disponível em: <www.ibge.gov.br>. Acesso em: 11 nov. 2015.

KLINK, C. A.; MACHADO, R. B. A conservação do Cerrado brasileiro. Megadiversidade, v. 1, n. 1, p. 147-155, 2005.

MARTINS, R. História do Paraná. 3. ed. Curitiba: Guaíra Limitada, 1937. 
MEDEIROS, R. Contribuição das Unidades de Conservação brasileiras para a economia nacional: sumário executivo. Brasília: MMA, 2011.

PÁDUA, M. T. J. O fim da APA de Guaraqueçaba? O Eco, 19 de setembro de 2006. Disponível em: http://www.oeco.org.br/colunas/maria-tereza-jorge-padua/16284-oeco-18681/ Acesso em 13/01/2016.

PÉREZ, M. S.; GÓMEZ, J. R. M. Políticas de desenvolvimento da pesca e a aquicultura: conflitos e resistências nos territórios dos pescadores e pescadoras artesanais da Vila do Superagüi, Paraná, Brasil. Sociedade \& Natureza, Uberlândia, v. 26, n. 1, p. 37-47, 2014.

PIERRI, N.; ANGULO, R. J; SOUZA, M. C; KIM, M. K. A ocupação e o uso do solo no litoral paranaense: condicionantes, conflitos e tendências. Desenvolvimento e Meio Ambiente, n. 13, p. 137-167, 2006.

RFFSA. 1885-1985 Ferrovia Paranaguá Curitiba: uma viagem de 100 anos. RFFSA, 1985.

SEZERINO, F. S.; TIEPOLO, L. M. O Programa Minha Casa Minha Vida e seus efeitos sobre as área protegidas: um estudo de caso na Mata Atlântica Paranaense. In: Hanazaki, N.; Herbst, D. F.; Ávila, J. V. C.; Heineberg, M. R.; Gomes, T. C. C. (Orgs.) Culturas e biodiversidade: o presente que temos e o futuro que queremos. VII Sapis, II Elapis. Florianópolis, 2015.

SOARES, D. G.; IRVING, M. A. Entre a "Paz" e a "Corrente": conflitos no Parque Estadual da Pedra Branca - RJ. In: Irving, M. A. (Org.). Áreas protegidas e inclusão social: construindo novos significados. Rio de Janeiro: Fundação Bio-Rio, 2006.

SNUC. Sistema Nacional de Unidades de Conservação da Natureza. Lei $n^{\circ}$ 9.985, de 18 de julho de 2000, e Decreto $n^{\circ} 4.340$, de 22 de agosto de 2002.

TAUNAY, A. D. História das bandeiras paulistas. Salvador: Centro de Documentação do Pensamento Brasileiro, 2012. v. 1.

WRI. A. Estratégia global da biodiversidade: diretrizes de ação para estudar, salvar e usar de maneira sustentável e justa a riqueza biológica da Terra. Washington: World Resources Institute, 1992.

Artigo recebido em 30/07/2015. Aceito para publicação em 18/11/2015. 